\title{
Design-based research with mARC ID model: designing experiential learning environments
}

\author{
Slaviša Radović ${ }^{1}$ (D) . Hans G. K. Hummel ${ }^{1} \cdot$ Marjan Vermeulen $^{1}$
}

Received: 29 March 2021 / Accepted: 11 October 2021 / Published online: 18 October 2021

(c) The Author(s) 2021

\begin{abstract}
The relationship between experience (through practice) and knowledge (by theory) is becoming increasingly important in contemporary educational research and development. Where educational curricula aim to support students in linking practical experience to their academic knowledge development, experiential learning appears complex to design with high instructional prerequisites that make it difficult to achieve. This article reports the process of redesigning an experiential learning environment throughout iterative designbased research. For reasons of methodological consistency, we first introduce and discuss the mARC instructional design model that identifies three pillars of experiential learning (more Authenticity, Reflection, and Collaboration). We then present three empirical studies of how the implementation of the mARC model affected the quality of learning process and outcomes. The results of our design-based research show that the model offers powerful practical guidelines for experiential learning design. Application of the model: (a) improved students' academic achievement, (b) helped students to engage with both re- and de-contextualisation of knowledge, and (c) improved reflection processes during learning. The study suggests that experiential learning, aligned with the pillars of mARC model, can successfully support learners in their effort to create knowledge through practical experience.
\end{abstract}

Keywords Authenticity · Collaboration · Experiential learning · Instructional design · $\mathrm{mARC} \cdot$ Reflection

\section{Introduction}

In recent decades, the necessity of lifelong learning has become a popular driver of many educational reforms and policy plans (OECD, 2019). In the context of higher education, more attention has been given to supporting students in linking their learning experiences in practice to academic knowledge growth (Heinrich \& Green, 2020). Experiential learning theory, as developed by Kolb (1984), recognises that bridging

Slaviša Radović

slavisa.radovic@ou.nl

1 Faculty of Educational Sciences, Open University of the Netherlands, P.O. Box 2960,

6401 DL Heerlen, The Netherlands 
practical experience and theoretical knowledge is crucial for education. Kolb (1984) describes learning as a cyclic process of four steps: concrete experience $(\mathrm{CE})$, reflective observation (RO), abstract conceptualization (AC) and active experimentation (AE). While learners follow the cyclic steps, they get the opportunity to construct knowledge arising from concrete learning experiences and converting it into abstract generalizations (de-contextualising knowledge), but also from applying this new generic knowledge in other learning experiences (re-contextualising knowledge) (Lindsey \& Berger, 2009; Radović et al., 2021c; Reigeluth \& Carr-Chellman, 2009).

Within formal education, several learning benefits are expressed for experiential learning, especially supporting students in developing deeper understanding and broader knowledge (Kreber, 2001). Experiential learning also contributes to students becoming more thoughtful, reflective, and critical (Roberts, 2018). Furthermore, students report being more motivated, feeling better as a learner, and believing in the benefits of the course. Finally, literature indicates that students are encouraged to grow self-development skills and develop personal attitudes (personal attributes, communication abilities, self-awareness) when linking their learning experience to academic knowledge development (Coulson \& Harvey, 2013).

A recent review study (Radović et al., 2021c) of experiential learning revealed a variety of instructional strategies to use when supporting students, such as: providing real-world contexts of learning (including internships, practicums, fieldwork, observational activities, and service learning); offering more active learning (e.g. role-playing, serious games or simulations, research projects, case studies and scenarios, and various types of problem-based tasks); developing relevant knowledge, skills, and professional competencies in a work- or community-based learning context (including cognitive apprenticeships, guided participation, and legitimate peripheral participation); and often by engaging students with critical thinking, generalization, and reflection activities. However, although a number of instructional strategies and variants of experiential learning have been proposed (Bergsteiner \& Avery, 2014; Heinrich \& Green, 2020; Young et al., 2008), higher-education institutions are often criticised for failing to fully embrace experiential learning instruction (Groves et al., 2013; Roberts, 2018).

There are several learning design factors that lead to a superficial relation between experience and knowledge. First, educators have limited knowledge of design-based processes of developing experiential learning instruction (Kreber, 2001; Young et al., 2008). As a result, students report engaging in the experience at a superficial level, unable to perceive the authentic, reflective, or social aspects of the learning environment (Ash \& Clayton, 2004; Reeves et al., 2005). Second, educators miss the potential to deepen their educational design, instruction, assessment, and learning context in order to facilitate a more experiential learning process (Heinrich \& Green, 2020). Decisions need to be made about the learning content, authentic tools and resources, as well as timing of experiencing and reflecting, and sequencing these learning activities within the group of learners (Reeves et al., 2005). Making such instructional choices is the process which requires careful and rigorous planning. Finally, research suggests that instructional gaps in the learning design reduce educative opportunities and learning benefits (Kreber, 2001). Loosely-implemented learning designs could result in students' confusion and inability to follow the cyclic steps of experiential learning, as well as hinder knowledge de- and re-contextualisation (Heinrich \& Green, 2020; Radović et al., 2021d). 


\section{mARC ID model for more experiential learning}

Designing experiential learning in online education and adapting it to the needs of students in a specific context is not a simple and straightforward process (Radović et al., 2021d; Coulson \& Harvey, 2013; Heinrich \& Green, 2020). Situated in results of the recent review study that presented facilitating and hindering factors influencing experiential learning processes, Radović et al. (2021d) crafted mARC as an Instructional Design (ID) model for designing experiential learning environments. They first pointed out important instructional elements, then described and classified them and drew causal relationships, and finally provided design guidelines for applying the model (Fig. 1) (Radović et al., 2021d).

While the Kolb's model $(1984,2015)$ describes how experiences and abstract thinking influence each other, the mARC model points out a comprehensive set of instructional elements organized within the three pillars of Authenticity, Reflection, and Collaboration. Thus, three overall design requirements have to be met: a) Presence of real world context

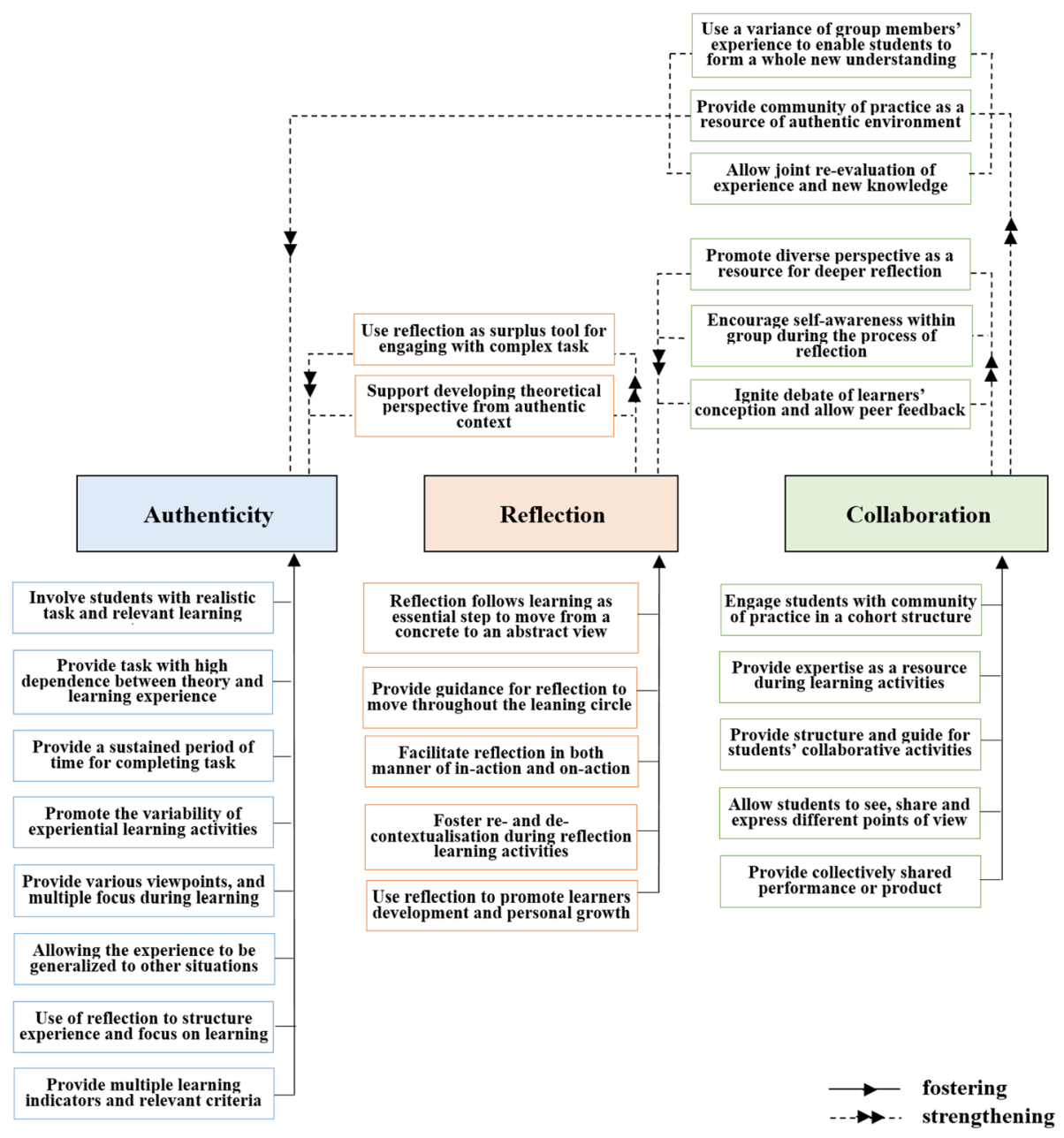

Fig. 1 mARC instructional design model 
to build academic knowledge over real practice settings (Authenticity); b) Possibilities for reflection during learning and experiencing (Reflection); and c) Construction of knowledge based on different perspectives and social learning activities (Collaboration) (Radović et al., 2021d).

Those building blocks can be found in other instructional requirements (Shambaugh \& Magliaro, 2001) and are mentioned by the National Society of Experiential Education (NSEE, 1998) as principles which underlie the excellence of pedagogy of experiential education.

\section{Iterative design approach with mARC}

The mARC model is designed to improve educational practice through an iterative process of design, development, implementation and analysis in real-world educational settings (Reeves et al., 2005). Figure 2 introduces three stages for developing complex and rich experiential learning environments (Plomp, 2007). The whole process is not carried out as completely predefined from the beginning, but it depends on the results of previous design stages. Hence, the knowledge generated during each stage of the design-based process is used to refine the following design stage, and as basis for the implementation of instructional elements of the following phases.

\section{Pillar of authenticity}

The idea that learning activities need to be more authentic and work-oriented was recognized during the mid-1980s (Villarroel et al., 2020). The National Society of Experiential Education (NSEE, 1998) underlines that the experience must have a real-world context and

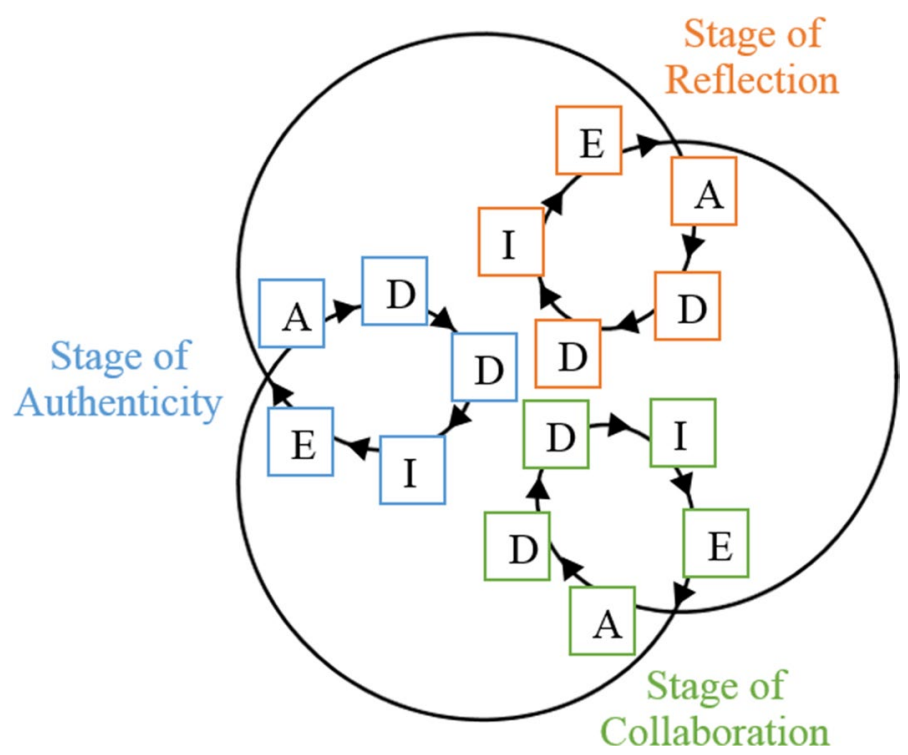

Fig. 2 Three stages of learning environment redesign cycle according to three pillars of mARC model (each including ADDIE phases) 
be meaningful in reference to an applied setting or situation. According to Gulikers et al. (2004), the authenticity of a learning environment is defined and determined by the extent to which professional situations, tools, and skills (represented in a learning environment) are relevant to the learner. This is extended by Mitchell (2008) who emphasises the importance of authentic social relations between faculty, student, and professional or service community during learning.

To ensure that experiential learning environments reflect the complexity of professional situations and work contexts mARC model suggest that students should be involved with realistic tasks and relevant learning (A1), where the task affords a high dependence between theory and learning experience (A2). It might be necessary to ensure that learners have sustained periods of time for completing task (A3) and observe the variability of experiential learning activities (A4). It is recommended that teachers provide various viewpoints on practice and multiple foci during learning (A5) and allow the learning experience to be generalized to other (different) situations (A6). Moreover, reflective learning activities should not only be seen as an extra layer of complexity, but also as a way to structure experience and focus on learning (A7). The final recommendation that arose from the pillar of authenticity of $\mathrm{mARC}$ is to provide multiple learning indicators and relevant criteria (A8) that learners have to meet in their real-life or carriers.

\section{Pillar of reflection}

Dewey (1933, p. 9) defined reflection as "the active, persistent and careful consideration of any belief or supposed form of knowledge in the light of the grounds that support it and the further conclusion to which it tends". Reflection is mentioned by NSEE (1998) as one of the key principles that transforms simple experience to a learning experience. Ash and Clayton (2004) have proposed three general perspectives of academic, personal, and civic reflection that maximizes learning. Furthermore, it is acknowledged that more-critical reflection enhances students' ability to question assumptions and values in an authentic context (Davis, 2003; Mitchell, 2008).

To support both a concrete and an abstract development, the mARC model suggests that reflection should follow learning as essential step (R1). Literature indicates that reflective thinking does not happen spontaneously and that reflection should almost always be explicitly encouraged (R2). This can be facilitated both in-action and on-action (R3). To ensure that the learning environment can support learners to understand knowledge and experience, reflection can be guided during both re-and de-contextualisation processes (R4). Furthermore, it could be necessary to ensure that learners identify personal assumptions and question their meaning, because reflection will not only challenge learning experience and developed knowledge, but its influence reaches beyond cognition (R5). Finally, to strengthen authenticity and develop coherent knowledge, reflection should be used as a surplus tool for engaging with the complexity of a task (R6) and for developing a theoretical perspective from an authentic context (R7).

\section{Pillar of collaboration}

The belief that knowledge is constructed through interaction with others is not new, but has gained more attention in educational research and practice (Lave \& Wenger, 1991; Raes et al., 2014; Teräs, 2016). Collaborative learning refers to an instructional strategy in which learners work actively together in groups with shared aims (Johnson \& Johnson, 
2009). Such relationships among learners should be designed to initiate critical discussions in which students can explore personal opinions and different viewpoints on the topic addressed (Mitchell, 2008). Furthermore, collaboration and interactions between different parties (faculty, student, and professional or service community) can further support students' perceptions of authenticity. Ash and Clayton (2004) found that peer support during reflection on learning helped learners to be critical of their own experience, placing it in context and expressing it concisely.

According to the mARC model, students should be engaged within a community of practice in a cohort structure $(\mathrm{C} 1)$ where they witness different expertise as a resource for learning (C2). Although learning in a group can be organized in various ways, students' collaborative activities should be structured and guided (C3) to support various learner processes and promote learning. Furthermore, it could be necessary to ensure that learners have the opportunity to learn from each other's differences and to see, share and express different points of view (C4). Experiential learning tasks should involve individuals working together to achieve common goals and to have collectively-shared performances or products (C5). Furthermore, the model suggests that authenticity should be strengthened and socially constructed within community of learners (C6) using the group members' experience when developing new understanding (C7) and throughout joint re-evaluation of experience and knowledge (C8). Finally, learners should be encouraged to reflect collaboratively using various perspectives that they have (C9). This can be achieved, for example, by encouraging self-awareness within groups during the process of reflection (C10) or initiating debate on learners' conceptions and allowing peer feedback (C11).

\section{Research questions}

To address how different pillars of experiential learning mutually influence and match each other, and how they impact learning outcomes, we report our iterative design-based research (DBR) using the mARC model for ID. The research was organised across three empirical iterations to disclose the possibilities of using mARC to redesign experiential learning instructions within a Master course for educational science students in higher education. The purpose of this article is not only to look for significant effects, but also to generate important practical insights for designing complex experiential learning instruction and rich learning experience (Reigeluth \& Carr-Chellman, 2009; Young et al., 2008). The research was designed to answer the following questions:

$R Q 1$ How does the systematic change in the learning environment relate to students' academic performance?

$R Q 2$ How does the systematic change in the learning environment relate to students' motivation for learning?

$R Q 3$ How does the systematic change in the learning environment relate to students' perception of experiential learning and authenticity?

The remainder of the article is organized as follows. In the next section, we present the iterative DBR research approach that we used to answer these research questions. After presenting the context of three studies, and after synthesizing the research results on experiential instructions, we conclude with a discussion of the three pillars for experiential learning. Findings and guidelines are seen as important for educators who desire to 
support their learners in their efforts to both increase their knowledge and learn by practical experiences.

\section{Research approach}

As we were interested in exploring this complex educational problem by using various instructional perspectives, we chose a design-based research (DBR) approach (Anderson \& Shattuck, 2012; Barab \& Squire, 2004; Plomp, 2007). "Design based research is grounded in the practical reality of the instructor, from the identification of significant educational problems to the iterative nature of the proposed solutions" (Reeves et al., 2005, pp. 107). In order to briefly explain the DBR process of this study, Table 1 gives an overview based on the generic model for design research (GMDR) of McKenney and Reeves (2012). During three research iterations, the Master course under investigation was redesigned within an educational setting by adding different variations of mARC elements (Fig. 2). In each study, students were divided into control and experimental groups, and the results are based on comparison against each other. Data were collected, analysed, and evaluated after each research stage, and the most optimal redesign was applied to the next course run in a cumulative approach (Barab \& Squire, 2004). The course was given two times a year and different students thus were participating each time.

In the first research stage, different levels of Authenticity were investigated. The findings of the first stage set the basic design for investigating the effects of the second pillar of Reflection. Hence, in the second research stage, the most effective authentic environment was used to investigate different levels of Reflection. Finally, in the third research stage of this iterative approach, the most optimal levels of Authentic and Reflective environments were used to investigate the optimal level of Collaborative reflection for effective experiential learning, within the third pillar. Table 1 presents the most important dependent variables that were measured throughout the DBR stages and studies.

Table 1 Outline of DBR based on McKenney and Reeves' (2012) generic model for design research (GMDR)

\begin{tabular}{|c|c|c|c|}
\hline Feature & Study 1 & Study 2 & Study 3 \\
\hline Number of participants & 37 & 84 & 50 \\
\hline Duration of the experiment period & Feb-May 2019 & Sept-Dec 2019 & Feb-May 2020 \\
\hline Research focus of experiment & Authenticity & Reflection & Collaboration \\
\hline \multicolumn{4}{|l|}{ Measuring instruments } \\
\hline Course academic report writing & $\mathrm{x}$ & $\mathrm{x}$ & $\mathrm{x}$ \\
\hline Questionnaire & $\mathrm{x}$ & $\mathrm{x}$ & $\mathrm{x}$ \\
\hline Student motivation* & $\mathrm{x}$ & $\mathrm{x}$ & $\mathrm{x}$ \\
\hline Perception of authenticity** & $\mathrm{x}$ & $\mathrm{x}$ & \\
\hline Perception of experiential learning $* * *$ & $\mathrm{x}$ & $\mathrm{x}$ & $\mathrm{x}$ \\
\hline Satisfaction with interactions $* * * *$ & & & $\mathrm{x}$ \\
\hline Reflection assignment & & $\mathrm{x}$ & $\mathrm{x}$ \\
\hline Students asynchronous discussion posts & & & $\mathrm{x}$ \\
\hline
\end{tabular}

Note: *Intrinsic Motivation Inventory (IMI) instrument from Ryan and Deci (2000); **5D framework for authenticity (5DF) instrument from Gulikers et al. (2004); *** Perception of experiential learning (EXP) instrument from Young et al. (2008); ****instrument from Driver (2002) and Lucas (2003) 
Design decisions were influenced by triangulation of both quantitative and qualitative research methods with respective statistical techniques (Anderson \& Shattuck, 2012). Multiple data sources were used (Table 1): final academic report assessments (as a measure of academic performance); students' written reflection assignment to a discussion forum (as a measure of the level of reflection); a posttest questionnaire with measures of motivation, perception of authenticity, and experiential learning; and debriefing activities to obtain more-qualitative insight into the learning process and opinions of participants.

Below, the context of the course and the most-effective experimental environment within each of these three research iterations are briefly described to illustrate how experimental learning environment was redesigned according to the model presented in Fig. 1. For the complete overview of these studies, we refer to Radović et al. (2020) for Study 1, Radović et al. (2021a) for Study 2, and Radović et al. (2021b) for Study 3.

\section{Context of the course and three studies}

DBR was situated in one course of a Master program for Educational Sciences at our university and conducted during three consecutive semesters (see Table 1). This Master is offered as distance learning and targets professionals in education who mainly are teachers seeking an academic degree and wanting to combine work with study. The course under study introduces students to important learning theories, both by studying theory and by experiencing these theories at work in actual practice. The course starts with a face-to-face introduction and the remainder continues online. Students and teachers interact through discussion boards and regular synchronous meetings in the Virtual classroom (Collaborate software).

The course allows students to study literature (AE), conduct an observational study of a classroom learning situation (CE), analyse a classroom learning situation from the theoretical perspective and with the tools of an educational researcher (RO) and, at the end, make generalizations from the concrete experiences through the lens of theory and methodology (AC) when writing an academic report. In their learning activities, students follow the four steps of experiential learning cycle by Kolb (1984) to facilitate both processes of re- and de- contextualisation (Radović et al., 2020).

\section{More authentic learning environment (Study 1)}

The first study aimed to find out how two different levels of authenticity (Less and More Authentic) in the course design correlate with students' learning outcomes. While the More Authentic course design offered students more freedom to choose a classroom learning situation to observe (task authenticity), high variability and availability of observation resources (physical context), and social interactions with a positive interdependence on the members (social context), students in the Less Authentic course variation were offered a set of prepared documents, a limited social context, and prearranged learning situation (all reducing the level of authenticity). We describe the More Authentic variant of the course, because it provided more benefits for students.

For a period of 11 weeks, the course guides students through complex observation assignment with series of learning tasks, while solving one complex assignment (A3). Students are gradually introduced to theoretical knowledge (e.g., different learning theories) and professional skills (such as arranging observation or preparing interview) (A2, A4). Students are expected to: 1) demonstrate knowledge by constructing an analysis instrument 
that is based on their knowledge of learning theories) (A6); 2) use professional skills (using research instruments, analysing data, and presenting results); and 3) create relevant and significant products for presenting their findings (poster presentation and an academic essay) (A1). To successfully accomplish the task, students have multiple learning foci (A5): by choosing the context for observation, by organising the observation, by making agreements with an educational institution, by preparing and objectively conducting the observation, by collecting and analysing data, and by reporting findings (A7). The course criteria, used to assess the academic reports, are similar for the evaluation of work in professional situations, such as a journal or conference paper review (A8).

\section{More reflection learning environment (Study 2)}

The findings of the first study set the basis for the second experiment. Therefore, in the second study, the most effective authentic environment (i.e., More Authenticity) was used to investigate the influence of different levels of Reflection (Less and More) and to understand how this support experiential learning. While students in the Less Reflection design were prompted toward providing evidence on understanding concepts and theory, or describing issues arising from concrete experience (Habitual actions and Understanding), students in the More Reflection course design were prompted to use practical context to think about theory (and vice versa) and to consider personal beliefs having direct influence on learning activity (Reflection and Critical reflection). The More Reflection design, as described below, facilitated students' deeper learning.

Five reflection tasks (R2) were designed to explicitly prompt students to: 1) re-capitalise on the relevant learning theme; 2) write a 300-word answer to the respective reflection prompt; and 3) share their writing with their peers by using the discussion forum after each study task. These reflection tasks were organised to follow the learning activities 1) at the time when students acquire learning experience (Reflection-in-action) or 2) when students need to examine experience using theoretical knowledge or professional skills (Reflectionon-action) (R3). Students were asked to reflect on choosing the context for observation, organising the observation, preparing and objectively conducting the observation, collecting and analysing data, and reporting findings, concepts and practical experiences (R1). To bridge the gap between theory and experience, students were prompted to re-contextualize theoretical knowledge in relation to practical situations, but also to find concrete arguments to de-contextualize their understanding (R4). Finally, to strengthen authenticity and develop coherent knowledge, students were guided while dealing with complexity of authentic context by focusing their thinking on the concreate experience that needs their attention and further analysis (R7, R6).

\section{More collaborative learning environment (Study 3)}

In the third and last study of our cumulative DBR approach, the findings of the first two experimental studies had set the basic design. Therefore, in the third study, the most-effective Authenticity and Reflection levels were used to study the influence of adding different levels of Collaborative Reflection elements.

Students were prompted not just to reflect and share their reflections, but also to discuss their reflections and different insights within a cohort $(\mathrm{C} 1)$. Because each of the reflection tasks followed specific learning assignments, students were discussing different perspectives and different points of view on their concrete learning experiences (C2). This was 
done online on the web platform that allowed students to communicate and discuss in a forum style. Discussions were led in threads that accompanied reflection assignments. Students were urged to act with openness and trust, as well as being stimulated to engage within the learning community (C9). They were asked to give compliments, provide assistance, highlight concerns, and suggest additional courses of action (C3). Following the model, collaborative activities were used to socially construct and strengthen authenticity (e.g. collaboratively reflect on an authentic experience) (C7), but also to support reflection processes (e.g. questioning personal assumptions when considering multiple perspectives) (C8). Students had various opportunities to witness each other's differences, to see, share and express different points of view (C4), and to discuss collectively shared understanding (C5).

\section{Overall results}

Results of data analysis along the way directed the cumulative design of sequential experiential learning environments, as described in the previous sections, for the course under study. We used various measuring instruments (see Table 1) to analyse the effects of each design iteration on students' achievement, motivation, and perceptions of experiential learning and authenticity. In Table 2, we summarize the statistically-significant results for each outcome variable. As non-parametric tests were run in the separate studies, we do not report effect sizes in this article, but $p$ values obtained from Mann-Whitney and Kruskal-Wallis tests. Results are briefly described and significant findings are related to the research questions, in order to illustrate how the systematic redesign of the learning environment influenced learning, as can be observed from increased scores on the output variables (as mentioned in Table 2). For a complete overview of results, we refer to Radović et al. (2020) for Study 1, Radović et al. (2021a) for Study 2, and Radović et al. (2021b) for Study 3.

\section{Quality of academic performance}

Effects on academic performance were measured through assessment of students' final course assignment (writing an academic report). Assessment criteria included the extent to which students apply theory to practice and to which they extract and report theoreticallyrelevant meanings from a practical situation.

Statistical analysis revealed no significant effect of the different levels of authenticity on academic performance, although participants in the More Authentic group had a tendency

Table 2 Overall results

\begin{tabular}{llll}
\hline Variable & Study 1 & Study 2 & Study 3 \\
\hline Quality of academic performance & n.s & $p=.039$ & n.s \\
Quality of reflection & $*$ & $p<.001$ & $p=.038$ \\
Perception of motivation & (high) n.s & (high) n.s & (high) n.s \\
Perception of quality of experiential learning & $p=.081$ & n.s & n.s \\
Perception of authenticity & $p=.016$ & $p=.07$ & $/$ \\
\hline
\end{tabular}

Note: * does not apply here; / not measured; high - ceiling effect as a results of high ratings; n.s. - comparison between groups not significant 
to score higher on all course criteria. When adding the instructional elements of reflection in the second study, students in the More Reflection variation of the course outperformed other students $(p=0.039)$. On subscale level of academic performance, a marginal statistical difference $(p=0.091)$ was evident for their quality of scientific reporting (quality of the introduction, general theoretical framework, methods, results, conclusion and discussion sections). For the quality of the content criteria for academic performance, students in the More Reflection condition described practice better, demonstrated theoretical knowledge better, and were more successful in analysing this practice through a theoretical lens $(p=0.032)$.

Finally, regarding the third study and the contribution of a More Collaborative Reflection environment, no significant differences were observed for Academic performance. However, an analysis of demographic characteristics suggest that More Collaborative Reflection settings support shared understanding and benefit all students equally. This finding is in contrast with the previous two studies that found that older students, as well as students with more work experience and those students coming from research universities, obtained better academic performance scores than younger students who were less experienced and came from higher vocational education.

\section{Quality of reflection}

Finally, the benefits from the More Reflection condition were manifested by students achieving higher Quality of reflection $(p<0.001)$. The second study revealed that More Reflection prompted students to reach the level of critical reflection. Regarding the third study and the impact of a More Collaborative Reflection environment, an important contribution from the Collaboration pillar could be mentioned. Students were able to achieve higher levels of reflection $(p=0.038)$. Discussions triggered reflection and higher-order thinking, as well as helping students to make their thoughts explicit in a social context.

\section{Students' motivation}

With regard to students' motivation, measured by the Intrinsic Motivation Inventory (IMI) instrument (Ryan \& Deci, 2000), correlation analysis indicated a positive relationship between the dimensions of motivation (perceived interest and value) and perceptions of authenticity and experiential learning. Overall perceptions of motivation, authenticity and experiential learning were dependent on each other, and interlinked rather than discrete and disconnected. Additionally, more-complex learning instructions including reflection in the second study and collaboration in third study did not lead to a decrease in students' motivation, perceptions of usefulness, interest and enjoyment during learning. Each subscale of the questionnaire was almost equally and highly rated in all three studies.

\section{Perception of quality of experiential learning}

The third research question focused on the effect of DBR on the quality of experiential learning. In all three studies, we used a questionnaire from Young et al. (2008) with four dimensions that estimate learners' awareness of: Active Experimentation (AE) and Concrete Experience (CE), as two steps of Re-Contextualisation; and Reflective Observation (RO) and Abstract Conceptualization (AC), as two steps of De-Contextualisation. 
The first study demonstrated a tendency for students in More Authenticity to perceive their learning environment as more experiential $(p=0.081)$ and to rate the re-contextualisation process statistically-significantly higher than students receiving Less Authenticity ( $p=0.033)$. We could observe that: 1) new learning experiences or professional situations were encountered (CE); and 2) experimenting with course concept and theories was done in order to improve understanding (AE). On the other hand, there was no effect on the decontextualisation process of experiential learning.

Analysis for the second and the third studies revealed that students perceived all four steps of experiential learning ( $\mathrm{CE}, \mathrm{RO}, \mathrm{AC}$, and $\mathrm{AE}$ ) as equally important (i.e. with equally- high scores), without significant differences between the groups. Although prompting reflection positively influenced students' learning results and academic performance, it did not influence the (already high) rating of experiential learning. Similar results were found in the third study.

\section{Perceptions of authenticity}

Finally, we examined students' perceptions of their possibilities to apply knowledge in the context of the (future) work environment by using professional skills and tools. Gulikers et al.'s (2004) 5D framework was used to measure their perception of authenticity.

During the first study, students in More Authentic environment agreed on the relevance of authenticity, and clearly valued the contextualisation of learning in a context that mirrors professional work. Perceptions of overall authenticity were significantly higher in the More Authentic group $(p=0.016)$ compared with the Less Authentic group. Furthermore, the second study revealed that systematic prompting in the More Reflection group had a positive influence on perceptions of authenticity $(p=0.07)$. It seems that reflection helps students to engage better with authentic professional situations and contexts which are reassembled in the learning environment. Students were able to perceive various opportunities to make a connection between knowledge and practical experience when they used professional tools, knowledge and skills, and when they imitated behaviour of experts.

\section{Discussion}

The purpose of this study was to share some overall insights into how practitioners can systematically redesign and conceptualize more experiential learning environments within higher (online) education. The mARC model described in this article provides a useful framework to guide the design of learning environments to support learners in their efforts to create knowledge through practical experience. This article further evaluates the overall suitability of the model and the evidence from three underlying studies. Based on that model and our empirical findings, we first present relevant conclusions for the three pillars of experiential learning, followed by some practical implications (Table 3).

The first study showed that instructional authenticity elements better relate concrete learning experiences with knowledge development, and provide several other benefits for learning. They cater for students learning to use professional tools, knowledge and skills when engaging in all four steps of experiential learning (and facilitated both re- and decontextualization of knowledge). Furthermore, perceptions of authenticity, motivation and experiential learning appeared to be related. These results are in line with Herrington et al. (2010, p.19) who acknowledged that an authentic context provides "the purpose and 


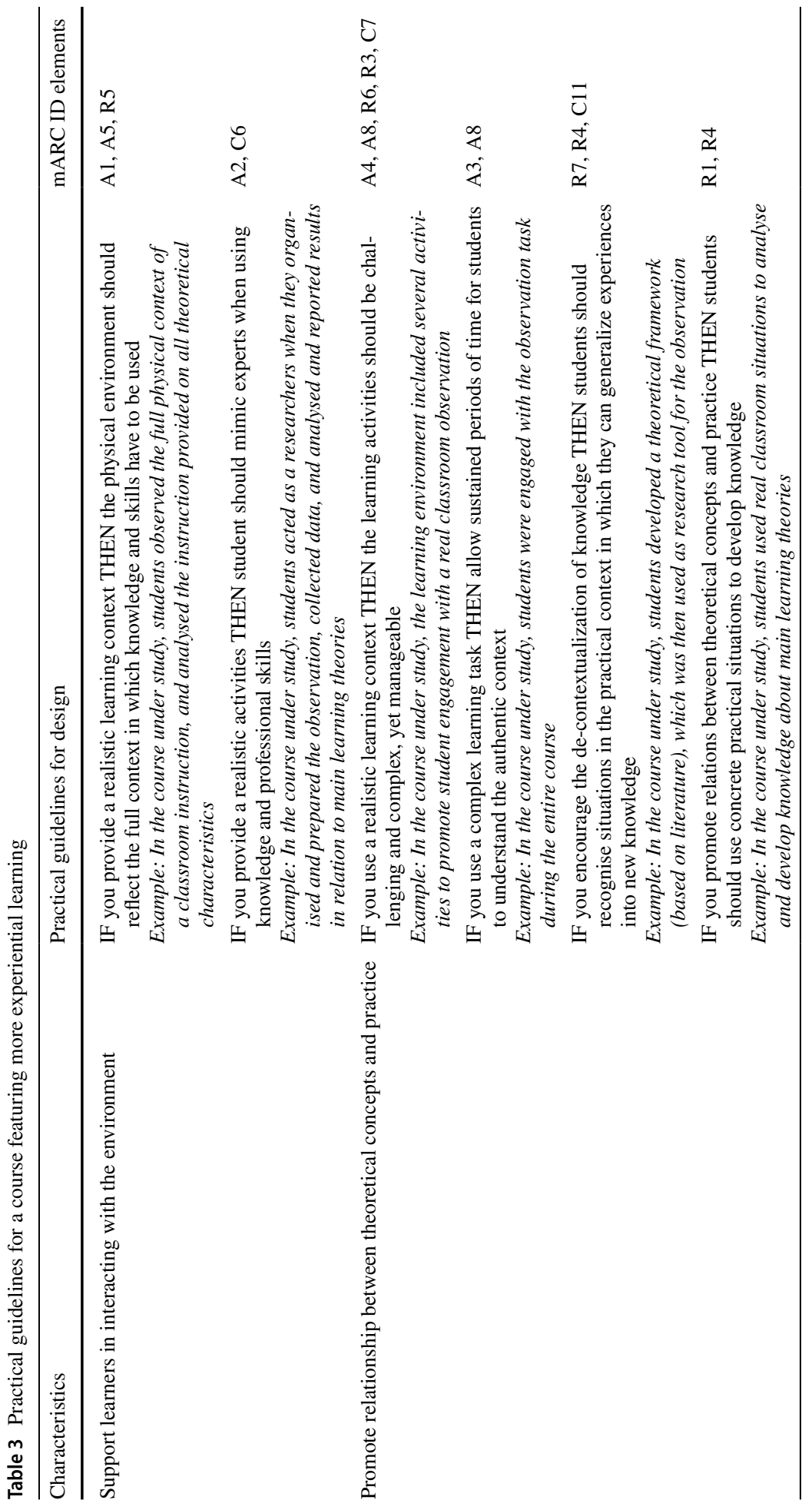




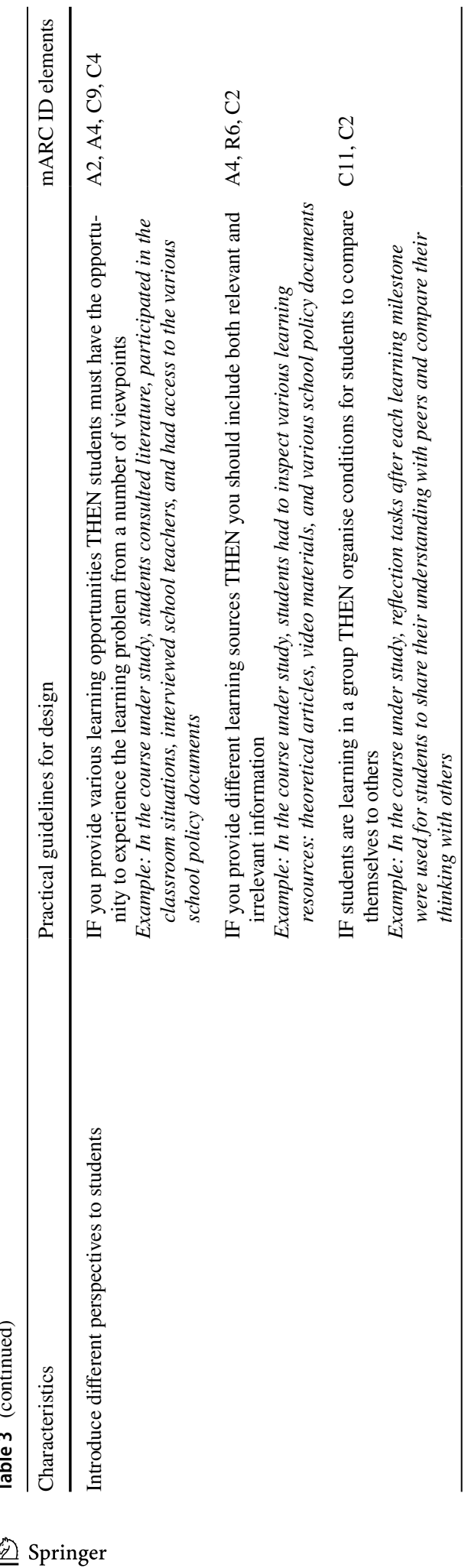




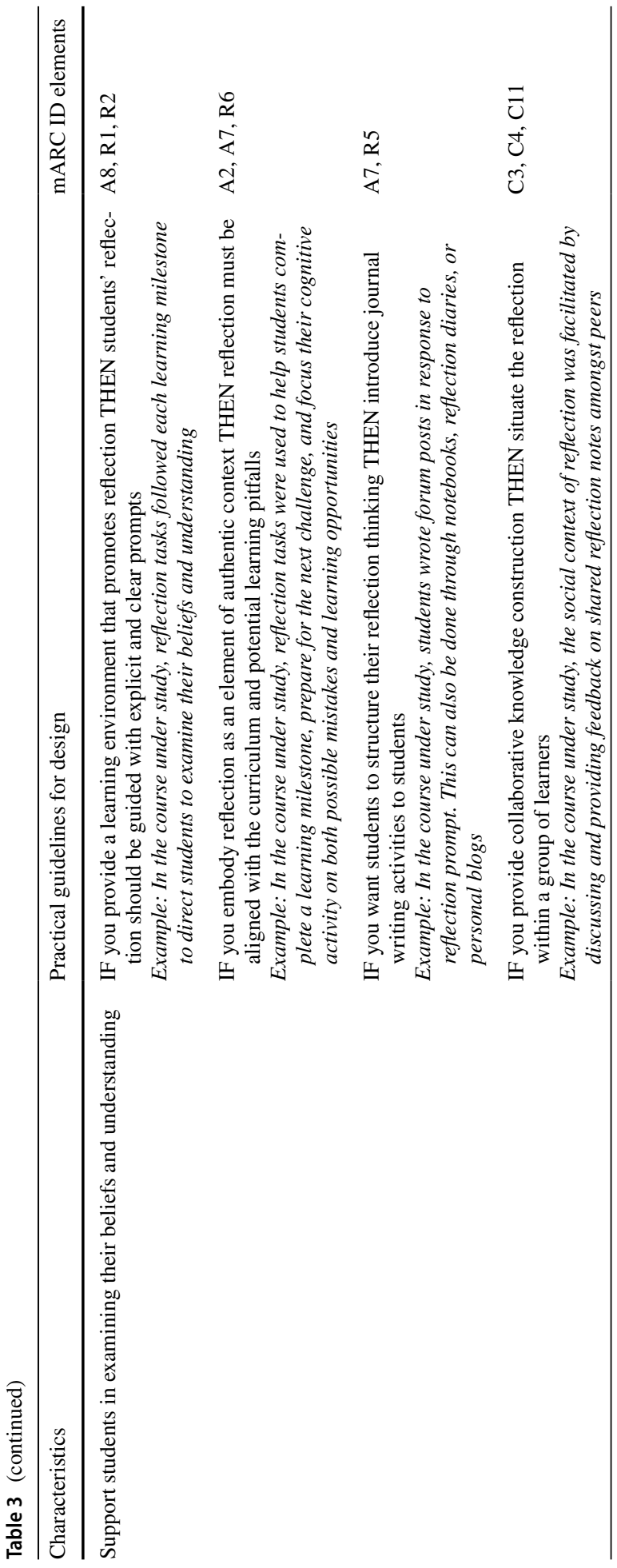




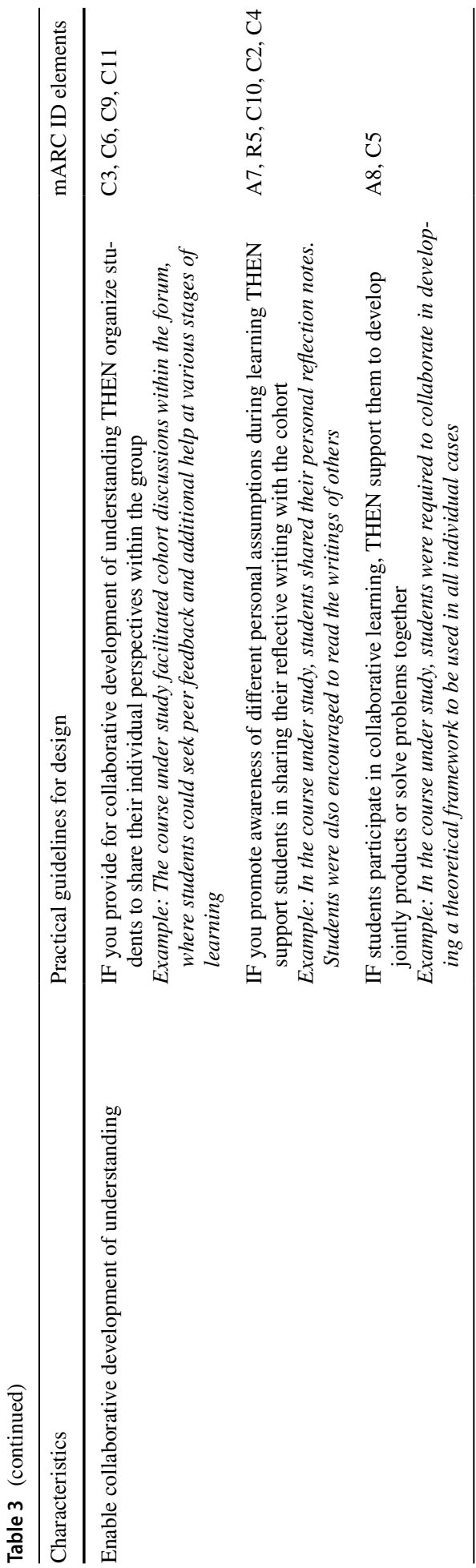


motivation for learning, and a sustained and complex learning environment that can be explored at length". However, although learning activities allowed the experience to be generalized to other (different) situations, it did not influence students' academic performance. These findings deepen understanding of how authentic learning can be enhanced (and supplemented) to achieve more learning benefits.

The second study revealed that using instructional reflection elements improves academic learning outcomes. These findings are in line with Coulson and Harvey (2013) who found that reflective practice incorporated into curriculum together with authentic learning enables students to reach a better understanding when learning through experience. In the work of Davis (2003), such prompts were seen to promote the knowledge-integration process of identifying weaknesses in learners' knowledge. Our study revealed that more reflection prompts can support students to develop academic ways of thinking, to further generalise their experience, and to achieve better academic results. It should be noted that reflection can be used for engaging students with the complexity of authentic tasks and for developing a theoretical perspective from an authentic context. These two important features of more reflection environments strengthened students' perception of authenticity and gave them more opportunities to examine personal beliefs of practical experience to construct theoretical concepts.

Third, in the final study, the third pillar of the mARC model had a positive impact on various aspects of the learning process. It enhanced individual reflection and interaction between peers, as well as promoting collaborative knowledge construction in a way that led (less experienced and younger) students to use the group members' experiences to form new understanding and share reflective thinking (Radović et al., 2021b). A similar conclusion was reached by Raes et al. (2014), who found that sharing and discussing ideas about authentic learning material in small groups gives all students the opportunity to express their thoughts, while especially supporting low-achieving science students. In our study, this was achieved within a cohort structure, with students also witnessing different expertise as a resource for learning and understanding. According to Lindsey and Berger (2009) and Coulson and Harvey (2013), instead of simplifying the design, learners should be provided with appropriate social and collaborative contexts to help them to deal with the complexity of knowledge construction complexity rather than to avoid it. Our study showed that sharing and discussing reflective thinking with peers in a collaborative setting promoted more critical thinking and improved students' levels of reflection.

Two limitations of this study should be taken into account. First, the basic settings of DBR (using the same course over all three iterations of the research to achieve a cumulative research approach) limited the selection of participants. To maintain the same context, we were not able to include students from other courses or other faculties (Plomp, 2007). Second, by being situated in a real educational environment during the formal educational process, our research design had to comply with various policies and principles that have been developed to maintain educational quality (Anderson \& Shattuck, 2012). For example, constrained by the educational vision, rules of examination and ethical issues of our university, we were not in a position to include more experimental variety in conditions by: 1) making even greater difference between two authentic environments, 2) making reflective assignments compulsory as part of students' assessment, and 3) placing students in smaller groups with products that had been collectively worked out.

In terms of recommendation for further research, it is evident that all three pillars of the mARC model were important for redesigning rich and complex experiential learning environment. A question that remains is whether the same research results would be obtained with just one more-complex stage of development? We believe that this cumulative 
approach would be possible, because the links between fostering and strengthening elements within the model are clearly highlighted (see Fig. 2 and explanations in Sect. 4). Even more importantly, the mARC model is supposed to be used during a three-step DBR process, but this does not mean that the mARC model loses its applicability after three cycles of iteration. To facilitate the pursuit of more experiential learning, it is probably necessary to research the model while applying more cyclical iterations (Anderson \& Shattuck, 2012). Finally, while we found that higher levels of the main instructional elements improve experiential learning, it is important for researchers using the mARC model to find the optimal complexity of these instructional elements. That is, a balance should be found between maximizing learning outcomes without creating an overwhelming (and costly) learning activity that could paralyze learners' knowledge growth (Radović et al., 2021d).

Taken altogether, the findings of this study suggest that the mARC model provides a useful framework to guide the design of learning environments to support learners in their efforts to create knowledge through practical experience. The following five suggestions are intended to help practitioners to successfully facilitate more experiential learning. First, students should be supported to interact with the environment in an authentic way and through authentic activities. Second, students should be able to practise theory and theorize practice while alternating often between the two. Third, students should have the opportunity to experience the learning problem from a number of perspectives. Fourth, explicit and clear reflection prompts should be used to allow students to examine their beliefs, understandings, and knowledge. Students should be continually encouraged to share and discuss their reflections. Finally, students should be enabled to develop understanding and critical attitudes toward each other's contributions and ideas. These five general characteristics are presented in Table 3, where they are complemented by more-specific practical guidelines for designing learning processes, provided with concrete examples from our study, and related to mARC ID elements.

Open Access This article is licensed under a Creative Commons Attribution 4.0 International License, which permits use, sharing, adaptation, distribution and reproduction in any medium or format, as long as you give appropriate credit to the original author(s) and the source, provide a link to the Creative Commons licence, and indicate if changes were made. The images or other third party material in this article are included in the article's Creative Commons licence, unless indicated otherwise in a credit line to the material. If material is not included in the article's Creative Commons licence and your intended use is not permitted by statutory regulation or exceeds the permitted use, you will need to obtain permission directly from the copyright holder. To view a copy of this licence, visit http://creativecommons.org/licenses/by/4.0/.

\section{References}

Anderson, T., \& Shattuck, J. (2012). Design-based research: A decade of progress in education research? Educational Researcher, 41(1), 16-25.

Ash, S. L., \& Clayton, P. H. (2004). The Articulated Learning: An approach to guided reflection and assessment. Innovative Higher Education, 29, 137-154.

Barab, S., \& Squire, S. (2004). Design-based research: Putting a stake in the ground. Journal of the Learning Sciences, 13(1), 1-14.

Bergsteiner, H., \& Avery, G. (2014). The twin-cycle experiential learning model: Reconceptualising Kolb's theory. Studies in Continuing Education, 36(3), 257-274.

Coulson, D., \& Harvey, M. (2013). Scaffolding student reflection for experience-based learning: A framework. Teaching in Higher Education, 18(4), 401-413.

Davis, E. (2003). Prompting middle school science students for productive reflection: Generic and directed prompts. Journal of the Learning Sciences, 12(1), 91-142. 
Dewey, J. (1933). How we think: A restatement of the relation of reflective thinking to the educative process. Henry Regnery Co.

Gulikers, J. M., Bastiaens, T. J., \& Kirschner, P. A. (2004). A five-dimensional framework for authentic assessment. Educational Technology Research and Development, 52(3), 67-86.

Heinrich, W. F., \& Green, P. (2020). Remixing approaches to experiential learning, design, and assessment. Journal of Experiential Education, 43(2), 205-223.

Johnson, D. W., \& Johnson, R. T. (2009). An educational psychology success story: Social interdependence theory and cooperative learning. Educational Researcher, 38(5), 365-379.

Kolb, D. (1984). Experiential learning: Experience as the source of learning and development. Prentice-Hall.

Kolb, D. (2015). Experiential learning: Experience as the source of learning and development. Pearson Education.

Kreber, C. (2001). Learning experientially through case studies? A conceptual analysis. Teaching in Higher Education, 6(2), 217-228.

Lave, J., \& Wenger, E. (1991). Situated learning legitimate peripheral participation. Cambridge University Press.

Lindsey, L., \& Berger, N. (2009). Experiential approach to instruction. In C. Reigeluth, \& A. Carr-Chellman (Eds.), Instructional-design theories and models: Building a common knowledge base (Vol. III) (pp. 117-142). New York, NY: Routledge.

Lucas, S. B. (2003). Asynchronous discussion groups in teacher training classes: Perceptions of native and non-native students. Online Learning Journal, 7(3), 24-46.

McKenney, S., \& Reeves, T. C. (2012). Conducting educational design research. Routledge.

Mitchell, T. D. (2008). Traditional vs. critical service-learning: Engaging the literature to differentiate two models. Michigan Journal of Community Service Learning, 14(2), 50-65.

National Society of Experiential Education (1998). Eight principles of good practice for all experiential learning activities. Paper presented at the 1998 Annual Meeting, Norfolk, VA. Retrieved from: http:// www.nsee.org/8-principles

OECD. (2019). Envisioning the future of education and jobs: Trends, data and drawing. Paris: OECD Publishing. Available at: http://www.oecd.org/education/Envisioning-the-future-of-education-and-jobs.pdf

Plomp, T. (2007). Educational design research: An introduction. In T. Plomp \& N. Nieveen (Eds.), An introduction to educational design research. Enschede, the Netherlands: SLO.

Radović, S., Firssova, O., Hummel, H. G. K., \& Vermeulen. M. (2020). Strengthening the ties between theory and practice in higher education: an investigation into different levels of authenticity and processes of re- and de-contextualisation. Studies in Higher Education. https://doi.org/10.1080/03075079. 2020.1767053.

Radović, S., Firssova, O., Hummel, H. G. K., \& Vermeulen. M. (2021a). Improving academic performance: strengthening the relation between theory and practice through prompted reflection. Active learning in Higher Education. https://doi.org/10.1177/14697874211014411.

Radović, S., Firssova, O., Hummel, H. G. K., \& Vermeulen. M. (2021b). The case of socially constructed knowledge through online collaborative reflection. Studies in Continuing Education (accepted for publication).

Radović, S., Hummel, H. G. K., \& Vermeulen, M. (2021c). The challenge of "more" experiential learning in master of education: systematic literature review. International Journal Of Lifelong Education (accepted for publication).

Radović, S., Hummel, H. G. K., \& Vermeulen, M. (2021d). The mARC instructional design model for more experiential learning in higher education: theoretical foundations and practical guidelines. Teaching in Higher Education. https://doi.org/10.1080/13562517.2021.1872527.

Raes, A., Schellens, T., \& De Wever, B. (2014). Web-based collaborative inquiry to bridge gaps in secondary science education. Journal of the Learning Sciences, 23(3), 316-347.

Reeves, T. C., Herrington, J., \& Oliver, R. (2005). Design Research: A socially responsible approach to instructional technology research in higher education. Journal of Computing in Higher Education, 16(2), 96-115.

Reigeluth, C. M., \& Carr-Chellman, A. A. (Eds.). (2009). Instructional-design theories and models: Volume III. Building a common knowledge base. New York: Routledge.

Roberts, J. (2018). From the Editor: The possibilities and limitations of experiential learning research in higher education. Journal of Experiential Education, 41(1), 3-7.

Ryan, R. M., \& Deci, E. L. (2000). Intrinsic and extrinsic motivations: Classic definitions and new directions. Contemporary Educational Psychology, 25, 54-67. 
Shambaugh, N., \& Magliaro, S. (2001). A reflexive model for teaching instructional design. Educational Technology Research and Development, 49, 69-92.

Teräs, H. (2016). Collaborative online professional development for teachers in higher education. Professional Development in Education, 42(2), 258-275.

Villarroel, V., Boud, D., Bloxham, S., Bruna, D., \& Bruna, C. (2020). Using principles of authentic assessment to redesign written examinations and tests. Innovations in Education and Teaching International, $57(1), 38-49$.

Young, M., Caudill, E., \& Murphy, W. (2008). Evaluating experiential leaning activities. Journal for Advancement of Marketing Education, 13, 28-40.

Publisher's Note Springer Nature remains neutral with regard to jurisdictional claims in published maps and institutional affiliations. 